\title{
Prediction of Critical Environments for Active-Passive Transition of Corrosion Resistant Alloys in Sour Environments
}

\author{
Akihiro MIYASAKA, Kozo DENPO and Hiroyuki OGAWA \\ Pipe and Tube Research Laboratory, Nippon Steel Corporation, Fuchinobe, Sagamihara, Kanagawa-ken, 229 Japan.
}

(Received on June 29, 1990; accepted in the final form on October 12, 1990)

\begin{abstract}
The corrosion behavior, in particular passivation, of corrosion resistant alloys (CRAs) in sour environments was investigated intensively by using a duplex stainless steel and an austenitic stainless steel as representative CRAs. It was found that hydrogen sulfide significantly retarded the passivation of CRAs, whereas carbon dioxide did not. The changes in corrosion morphologies due to the changes in environmental aggressiveness were classified on the basis of the immersion test results. A new criterion for predicting the critical environments for active to passive transition was proposed. The critical environments for the transition of a given alloy can be determined by comparing the $\mathrm{pH}$ of environments with the depassivation $\mathrm{pH}\left(\mathrm{pH}_{d}\right)$ of the material which is a function of environmental factors such as temperature and partial pressure of hydrogen sulfide. The locus of the points having $\mathrm{pH}=\mathrm{pH}_{d}$ gave a good estimation for the critical environments. It was confirmed that the prediction was in good agreement with the long-term immersion test results for 6 months. Since this criterion is based on the corrosion mechanism, it has many advantages; the prediction is accurate; the results for $\mathrm{CO}_{2}$-free environments can be extended to $\mathrm{CO}_{2}$-containing environments; and the prediction can be performed very quickly.
\end{abstract}

KEY WORDS: passivation; depassivation; stainless steel; sour gas; hydrogen sulfide; carbon dioxide; $\mathrm{pH}$.

\section{Introduction}

Oil and natural gas produced recently sometimes contain a large amount of hydrogen sulfide $\left(\mathrm{H}_{2} \mathrm{~S}\right)$ and carbon dioxide $\left(\mathrm{CO}_{2}\right)$. For the exploitation of such corrosive and hostile reservoirs, low alloy steel tubulars have been used traditionally with the application of corrosion inhibitors for preventing corrosion. Chemical inhibition, however, exhibit insufficient effect for very deep wells and is very expensive for offshore wells. Thus, completion with corrosion resistant alloys (CRAs) is becoming common practice. This is very attractive especially for offshore wells because chemical inhibition can be abolished. However, it is now well recognized, mainly on the basis of laboratory experience, that even CRAs exhibit localized corrosion, stress corrosion cracking and general corrosion. Some failures of CRAs in actual oilfields have been reported. ${ }^{1)}$

For the safe and economical use of GRAs, the selection of materials with necessary and sufficient corrosion resistance to a given environment is of great importance. This requires the precise determination of the application limit of each GRA. Many people have already proposed a variety of information concerning the application limits for a great number of CRAs. ${ }^{2)}$ However, extremely conservative materials have been chosen in many cases of actual application, presumably because the field performance estimated from laboratory data is often uncertain. The major reason for this uncertainty is that the results of conventional laboratory tests are greatly affected by experimental parameters such as test duration, applied stress and strain rate. For example, Chaung et al. ${ }^{3)}$ reported that SCC was observed for a G-ring test after two years from the initiation of the test.

Although conventional "go/no go" type SCC tests may rank the materials performance from the viewpoint of SGG resistance in a specific condition, they do not assure integrity in the actual material application to oilfields. In order to overcome this difficulty associated with laboratory tests, thorough understanding of the corrosion mechanism in sour environments is essential as well as the material evaluation criteria that are based on the corrosion mechanism.

Since GRAs are designed to be used in a passive condition, they cannot be used with integrity in an active condition. They must be passive in any circumstances of field application. If a criterion is obtained for the prediction of passive to active transition, a necessary condition for the safe use of CRAs can be determined; the environments where a given alloy can be passivated will be predicted. By estimating the critical conditions for an alloy to be active, the environments where the alloy cannot be used will be determined. It must be noted that the fact that an alloy is in a passive condition in a given environment does not necessarily means that the alloy can be used safely. There still remains the risk for localized corrosion and SCG. The critical condition for such material degradation must also be considered. The determination as to whether or not an alloy can be passive in an environment is also important to know the integrity of the alloy in an acid stimulation 
operation, where the alloy is subjected to very low $\mathrm{pH}$, typically 1 to 2 , aqueous solutions containing hydrogen sulfide and chloride.

In this study, the corrosion behavior of CRAs in sour environments is extensively investigated. On the basis of the results, a suitable criterion to determine the critical condition for the passivation limits of CRAs is proposed.

\section{Experimental}

\subsection{Test Materials}

Two stainless steels were subjected to investigation: one was an SUS316L (UNS S31603) austenitic stainless steel and another a duplex stainless steel of $22 \%$ Cr type in accordance with DIN standard 1.4462 (UNS S31803). Their chemical compositions are given in Table 1. Both steels were tested without cold working after final solution heat treatment.

\subsection{Test Procedure}

\subsubsection{Electrochemical Measurements}

To determine the depassivation $\mathrm{pH}\left(\mathrm{pH}_{a}\right)$, the changes in electrode potentials of specimens were measured. Test coupons of $3 \mathrm{~mm}$ thick, $15 \mathrm{~mm}$ wide and $20 \mathrm{~mm}$ long were machined from the middle of the plate thickness. They were degreased in acetone, polished with \#320 grit paper and coated with silicon resin leaving $1 \mathrm{~cm} \times 1 \mathrm{~cm}$ area for measurements. Just before immersed in test solutions, the specimens were pickled in $50 \%$ sulfuric acid at $333 \mathrm{~K}$ to remove the air-formed film. This means that the initial condition of the specimens was active. They were immersed in test solutions with various $\mathrm{pH}$ values adjusted before immersion. The changes in electrode potentials were continuously monitored for $8.64 \times$ $10^{4} \mathrm{~s}$. The final potential at the conclusion of immersion was adopted as a spontaneous potential in the environment and plotted as a function of solution $\mathrm{pH}$. The $\mathrm{pH}_{d}$ value was defined as the $\mathrm{pH}$ value at which the potential shifts in the positive direction on a potential-pH diagram.

DG polarization curves were measured following the same procedure of specimen preparation in the above to estimate the $\mathrm{pH}_{d}$. Potentiodynamic experiments were conducted at a scan rate of $50 \mathrm{mV} / \mathrm{min}$ either in the anodic or cathodic direction from the immersion potential at $300 \mathrm{~s}$ after being placed in the test solution.

Atmospheric pressure tests were made in glass cells, whereas high pressure and/or high temperature tests above $373 \mathrm{~K}$ were performed in high pressure autoclaves.

\subsubsection{Immersion Tests}

The relationship between environmental conditions and corrosion morphologies was examined by immersion tests. The dimensions of the test coupons were $2 \mathrm{~mm}$ thick, $15 \mathrm{~mm}$ wide and $20 \mathrm{~mm}$ long. They were degreased in acetone and polished with \#320 grit paper just before the tests. Atmospheric pressure tests were made in glass cells, whereas high pressure and/or high temperature tests above $373 \mathrm{~K}$ were performed in high pressure autoclaves. Test duration was primarily $1.21 \times 10^{6} \mathrm{~s}(336 \mathrm{~h})$. Tests for $1.56 \times$ $10^{7} \mathrm{~s}(4320 \mathrm{~h})$ were also conducted where the corrosion morphologies had been marginal after tests for $1.21 \times 10^{6} \mathrm{~s}$. After immersion, the corrosion morphology was determined for each specimen by visual and optical microscopic observations of the specimen surface. They were classified into four types shown in Fig. 1.

\subsection{Test Environments}

Deaerated aqueous solutions that contained 20 mass $\% \mathrm{NaCl}\left(4.28 \mathrm{~mol} / \mathrm{kg}-\mathrm{H}_{2} \mathrm{O}\right)$ and were in equilibrium with $\mathrm{H}_{2} \mathrm{~S}, \mathrm{CO}_{2}$ or argon at a scheduled partial pressure were selected as the test solutions. Ion exchanged and distilled pure water and analytical grade chemicals were used for preparing the test solutions. All the tests were conducted at elevated temperature ranging fom 298 to $523 \mathrm{~K} . \mathrm{H}_{2} \mathrm{~S}$ partial pressure was varied between 0.05 to $4 \mathrm{MPa}$.

\section{Results and Discussion}

\subsection{Passivation in $\mathrm{H}_{2} \mathrm{~S}$-containing Solution}

The corrosion potential of steel 316L after $8.64 \times$ $10^{4} \mathrm{~s}$ immersion with and without $\mathrm{H}_{2} \mathrm{~S}$ was plotted against solution $\mathrm{pH}$ and shown in Fig. 2 for the experiments at $298 \mathrm{~K}$. The $\mathrm{pH}_{a}$ values are indicated by upward arrows for both cases. Since an initial specimen surface in the $\mathrm{pH}_{d}$ measurements was in an active condition, this figure indicates that the steel can be passive in sour environments. The $\mathrm{pH}_{d}$ of 3.2 in a $0.1 \mathrm{MPa} \mathrm{H}_{2} \mathrm{~S}$ saturated solution was higher than that of 2.0 in an argon saturated solution. This implies that the passivation capability of the alloy decreased in $\mathrm{H}_{2} \mathrm{~S}$ environments compared with that without $\mathrm{H}_{2} \mathrm{~S}$. The similar increase in $\mathrm{pH}_{d}$ by presence of $\mathrm{H}_{2} \mathrm{~S}$ was reported by Miyuki et al. ${ }^{4}$ for a

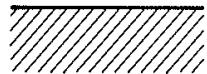

No $\operatorname{Attack}(\mathrm{N})$

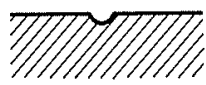

Slight Pitting Attack $\left(L_{1}\right)$ Shallow and Small

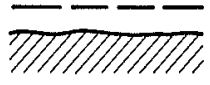

General Corrosion $(G)$

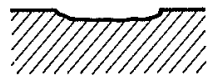

Severe Pitting Attack $\left(\mathrm{L}_{2}\right)$ Wide
Fig. 1. Classification of corrosion morphologies.

Table 1. Chemical compositions of test steels. (mass\%)

\begin{tabular}{cccccccccc}
\hline Code & $\mathrm{G}$ & $\mathrm{Si}$ & $\mathrm{Mn}$ & $\mathrm{P}$ & $\mathrm{S}$ & $\mathrm{Cr}$ & $\mathrm{Ni}$ & $\mathrm{Mo}$ & $\mathrm{N}$ \\
\hline 316L & 0.021 & 0.50 & 0.93 & 0.032 & $<0.001$ & 17.4 & 12.1 & 2.04 & - \\
DIN & 0.019 & 0.43 & 1.78 & 0.027 & $<0.001$ & 21.4 & 5.3 & 2.78 & 0.146 \\
\hline
\end{tabular}




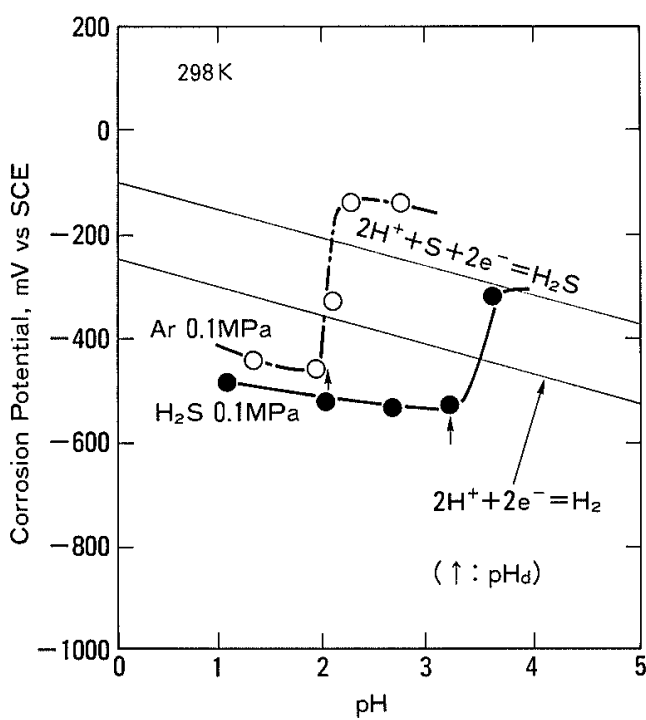

Fig. 2. Effect of solution $\mathrm{pH}$ on corrosion potential of stecl $316 \mathrm{~L}$ with and without $\mathrm{H}_{2} \mathrm{~S}$.

duplex stainless steel of $25 \%$ Cr type. The corrosion potential in an active state is slightly less noble than the equilibrium potential of hydrogen ion reduction reaction for both with and without $\mathrm{H}_{2} \mathrm{~S}$. The cathodic reaction occurring in this situation is thus considered to be the hydrogen ion reducing reaction.

The test results for steel DIN are shown in Fig. 3. The same tendency was observed for steel $316 \mathrm{~L}$ except that the corrosion potential for steel DIN in a passive state in an $\mathrm{H}_{2} \mathrm{~S}$-saturated solution was more negative than that for steel 316L. As shown in Fig. 3, the corrosion potential vs. $\mathrm{pH}$ relationship in a $\mathrm{CO}_{2}$ saturated solution agreed with that in an argon saturated solution. It is obvious from this result that $\mathrm{CO}_{2}$ does not affect the passivation behavior and the $\mathrm{pH}_{t}$ of CRAs.

The effects of temperature and $\mathrm{H}_{2} \mathrm{~S}$ partial pressure on the $\mathrm{pH}_{d}$ of steel DIN are given in Fig. 4. The $\mathrm{pH}_{d}$ value increased with a temperature rise and an increase in $\mathrm{H}_{2} \mathrm{~S}$ partial pressure. These results indicate that the passivation capability of the alloy decreases, in other words, the passive film becomes unstable, as temperature becomes high and/or $\mathrm{H}_{2} \mathrm{~S}$ partial pressure increases. In Fig. 4, equi- $\mathrm{pH}_{t}$ lines of $\mathrm{pH}_{d}=3.0,3.5,4.0$ and 4.5 are drawn on the basis of the test results. Almost the same tendency was obtained also for steel $316 \mathrm{~L}$.

The effect of $\mathrm{H}_{2} \mathrm{~S}$ on the anodic and cathodic polarization behavior of steel $316 \mathrm{~L}$ is shown in Fig. 5 . The corrosion current density increased approximately one order of magnitude in an $\mathrm{H}_{2} \mathrm{~S}$-saturated solution compared to that in an $\mathrm{H}_{2} \mathrm{~S}$-free solution. Both a critical passivation current density and passive current density in a passive region were enhanced by presence of $\mathrm{H}_{2} \mathrm{~S}$. The same tendency was also observed for steel DIN. The increase in passive current density in presence of $\mathrm{H}_{2} \mathrm{~S}$ was also reported by $\mathrm{Kudo}$ et $a l .5)$

\subsection{Passivation Mechanism in Sour Environments}

The passivation mechanism of stainless steels in

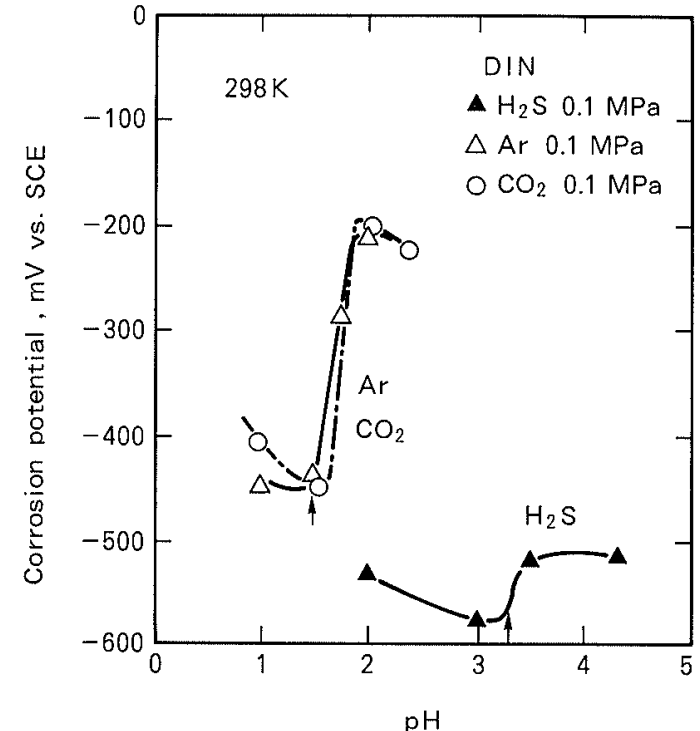

Fig. 3. Effect of solution $\mathrm{pH}$ on corrosion potential of steel DIN with and without $\mathrm{H}_{2} \mathrm{~S}$.

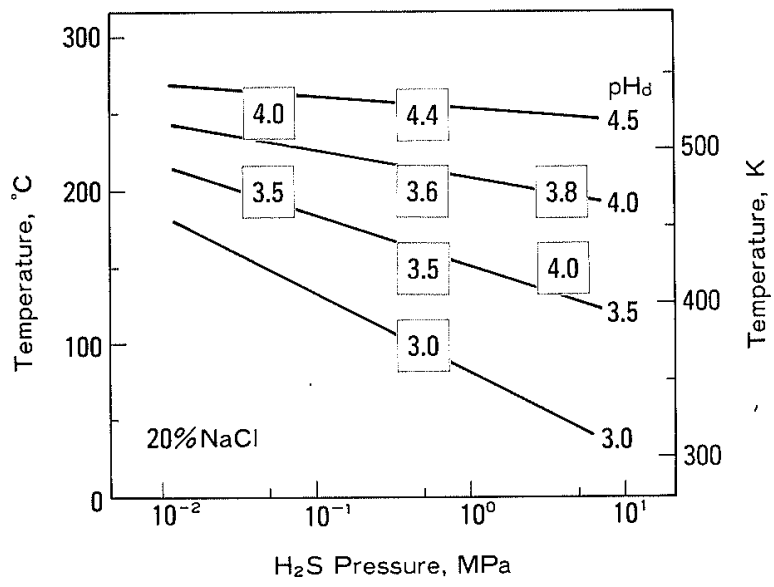

Fig. 4. Influence of temperature and $\mathrm{H}_{2} \mathrm{~S}$ partial pressure on $\mathrm{pH}_{d}$ of steel DIN in $20 \% \mathrm{NaCl}$ aqueous solution. Equi- $\mathrm{pH}_{a l}$ lines are drawn on the basis of the measured results.

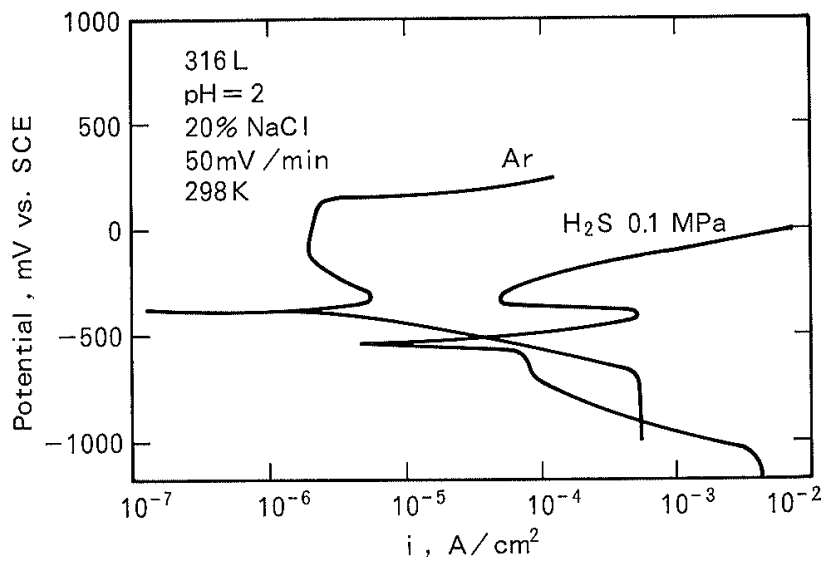

Fig. 5 Change in anodic and cathodic polarization curves of steel 316L with and without hydrogen sulfide.

presence and absence of oxygen was already discussed in detail by both Uhlig $^{6)}$ and Ogawa et al. ${ }^{7)}$ In absence of oxygen or other oxidant, the hydrogen ion is a passivator for the passivation of stainless steels. It should be noted that oxygen does not exist in sour 
environments. Here the mechanism of $\mathrm{pH}_{d}$ determination in sour environments is discussed by comparing the $\mathrm{pH}_{\iota}$ estimated from polarization curves with the measured $\mathrm{pH}_{d}$ values. The estimation of $\mathrm{pH}_{a}$ was performed by following approaches of Uhlig ${ }^{6)}$ and Leckie. ${ }^{8)}$

The $\mathrm{pH}_{a}$ is controlled by the balance of anodic and cathodic polarization as schematically illustrated in Fig. 6. Case (a) in Fig. 6 shows when the pH of a solution is higher than the $\mathrm{pH}_{a}$ of an alloy; both curves cross each other in a passive region on the anodic polarization curve. In a solution having lower $\mathrm{pH}$ than an alloy's $\mathrm{pH}_{d}$ (case (c)), two curves have an intersection in an active region. At $\mathrm{pH}=$ $\mathrm{pH}_{l}$, the two curves are situated at the case (b) at the transition between passivity and activity.

The following equation was assumed between critical passivation current density $i_{\text {crit }}$ and hydrogen ion concentration $\left[\mathrm{H}^{+}\right]$according to Uhlig ${ }^{6)}$ and Leckie. ${ }^{8)}$

$$
i_{\text {crit }}=K\left[H^{+}\right]^{\lambda}
$$

where, $K, \lambda:$ constants.

It has already been confirmed that this inverse linear relationship between the logarithm of the critical passivation current density and $\mathrm{pH}$ holds true for stainless steels in acid chloride environments. ${ }^{8)}$

In the case of active dissolution of CRAs in sour environments, the cathodic reaction is the reduction of hydrogen ion as mentioned before. The cathodic current then follows Tafel's equation in the following.

$$
E+\frac{2.3 R T}{F} \mathrm{pH}=b_{\mathrm{H}} \ln \frac{i_{\mathrm{II}}}{i_{\mathrm{II}}^{\circ}}
$$

where, $i_{\mathrm{H}}^{\circ}$ : an exchange current density of hydrogen evolution reaction.

When the $\mathrm{pH}$ of a solution is equal to the $\mathrm{pH}_{d}$ of an alloy, then $i_{\mathrm{H}}=i_{\text {crit }}$. By making use of these equations and substituting $E_{F}$, Flade potential, for the potential corresponding to $i_{\text {crit }}$, the following equation is obtained for estimation of $\mathrm{pH}_{d}$ on the basis of polarization curves.

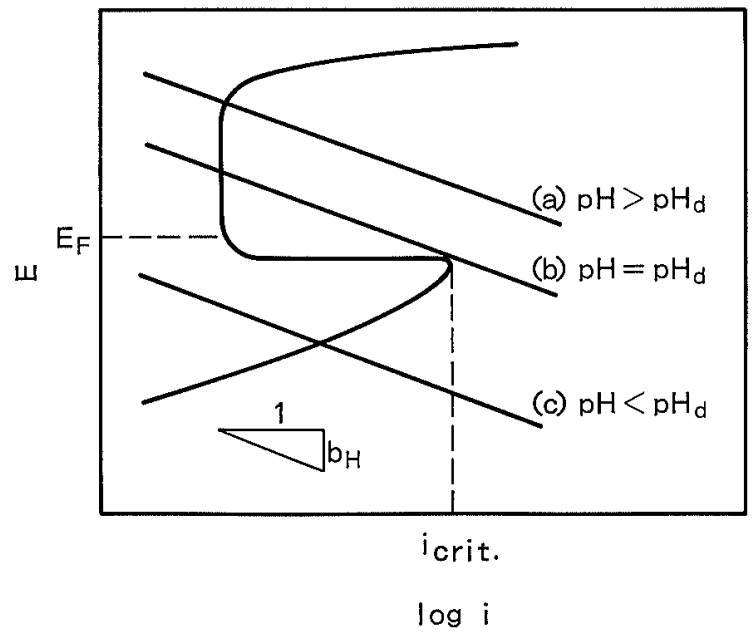

Fig. 6. Schematic illustration of anodic and cathodic polarization curves when the $\mathrm{pH}$ values are higher than, equal to and lower than $\mathrm{pH}_{\boldsymbol{a}}$.

$$
\mathrm{pH}_{d}=\frac{1}{2.3\left(b_{\mathrm{II}} \lambda+R T / F\right)}\left(2.3 b_{\mathrm{H}} \log \frac{\kappa}{i_{\mathrm{II}}^{\circ}}-E_{F}\right)
$$

If the $\mathrm{pH}_{d}$ estimated by the above procedure agrees with that determined by the potential measurements stated in Sec. 3.1, the mechanism of $\mathrm{pH}_{b}$ determination in sour environments mentioned previously will be confirmed.

The $i_{\text {crit }}$ and $E_{F}$ values were obtained from the polarization curves measured in an active region. They are plotted against $\mathrm{pH}$ in Fig. 7. An inverse linear relationship is observed between $\log i_{\text {crit }}$ and $\mathrm{pH}$, which was expected from Eq. (1). This means that the hydrogen ion reducing reaction is the cathodic reaction in an active state in $\mathrm{H}_{2} \mathrm{~S}$-containing environments.

The values of $\lambda$ and $K$ in Eq. (3) were obtained from the slope and the intercept on the abscissa in Fig. 7. The $b_{\mathrm{II}}$ was the Tafel slope of the cathodic polarization curves in an active region. The value of $i_{\mathrm{rr}}^{\circ}$ of $10^{-6} \mathrm{~A} / \mathrm{cm}^{2}$ was cited from the literature. ${ }^{9)}$ Though this reported value had been obtained at $298 \mathrm{~K}$, it was also used in $\mathrm{pH}_{d}$ estimation at thigher temperatures, because no data were available from the literature for $i_{\mathrm{II}}^{\circ}$ at elevated temperature.

The estimated values of $\mathrm{pH}_{d}$ for steel $316 \mathrm{~L}$ are tabulated in Table 2 together with the measured ones. The $\mathrm{pH}_{d}$ values estimated by the above calculation technique are in fairly good agreement with those measured. The similar good agreement was also obtained for steel DIN. Therefore it is confirmed that the $\mathrm{pH}_{l}$ in sour environments is controlled by the same mechanism as that in neutral chloride-containing aqueous solutions in absence of oxygen. The hydrogen evolution reaction controls the passivation of CRAs in sour environments.

\subsection{Corrosion Morphologies as a Function of Environmental Factors}

The relationship between the corrosion morpholo-

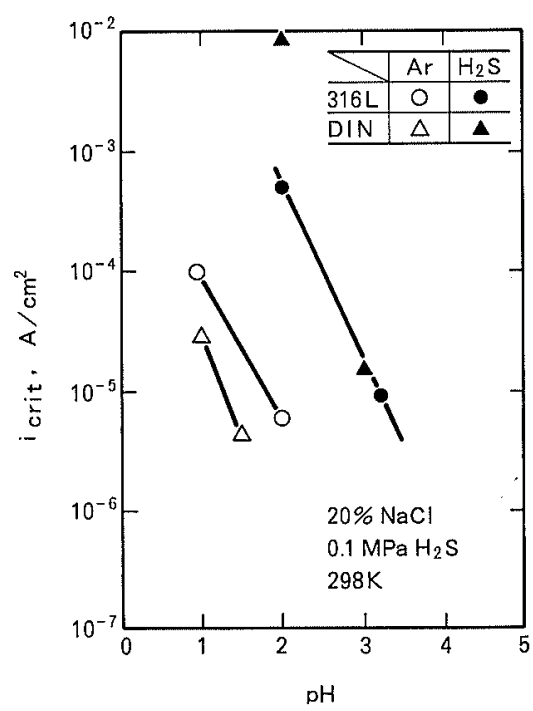

Fig. 7. Change in critical passivation current density $\left(i_{\text {crit }}\right)$ as a function of $\mathrm{pH}$. 
Table 2. Comparison of the $\mathrm{pH}_{d}$ values of steel $316 \mathrm{~L}$ estimated from polarization curves with those measured.

\begin{tabular}{cccccc}
\hline \multirow{2}{*}{$\begin{array}{c}\text { Temperature } \\
(\mathrm{K})\end{array}$} & \multicolumn{4}{c}{$\mathrm{H}_{2} \mathrm{~S}$ partial pressure (MPa) } \\
\cline { 3 - 6 } & $0 *$ & $10^{-3}$ & $10^{-2}$ & $10^{-1}$ \\
\hline \multirow{2}{*}{298} & Measured & 2.0 & 2.5 & 3.3 & 3.2 \\
& Estimated & 2.4 & 2.9 & 3.3 & 3.4 \\
\hline \multirow{2}{*}{323} & Measured & 2.0 & 3.3 & 3.3 & 3.3 \\
& Estimated & 2.4 & 3.2 & 3.4 & 3.0 \\
\hline \multirow{2}{*}{353} & Measured & 2.0 & 3.3 & 3.3 & 3.3 \\
& Estimated & 2.2 & 3.3 & 3.8 & 2.7 \\
\hline
\end{tabular}

* Deaerated with argon gas bubbling.

gies and the environmental conditions obtained as a result of immersion tests is illustrated in Fig. 8 for steel DIN. Almost the same results were obtained also for steel $316 \mathrm{~L}$. At $333 \mathrm{~K}$ with $\mathrm{H}_{2} \mathrm{~S}$ partial pressure of $0.05 \mathrm{MPa}$ (at the point D in Fig. 8), the alloy exhibited no attack $(\mathcal{N})$. The corrosion morphology changed to $L$ (localized corrosion) with a temperature rise and an increase in $\mathrm{H}_{2} \mathrm{~S}$ partial pressure. The steel finally exhibited general corrosion $(G)$ at high temperatures and high $\mathrm{H}_{2} \mathrm{~S}$ partial pressures.

Among the test results in Fig. 8, those for $\mathrm{H}_{2} \mathrm{~S}$ partial pressure of 0.05 and $0.5 \mathrm{MPa}$ and temperature of 333 and $423 \mathrm{~K}$ (points $\mathrm{A}$ to $\mathrm{D}$ ) were obtained after immersion for $1.56 \times 10^{7} \mathrm{~s}$. At $\mathrm{H}_{2} \mathrm{O}$ partial pressure of $0.5 \mathrm{MPa}$ and at $423 \mathrm{~K}$ (point $\mathrm{A}$ ), the corrosion morphology was at first determined as $L$ after immersion for $1.21 \times 10^{6} \mathrm{~s}$, where on the other hand that after $1.56 \times 10^{7} \mathrm{~s}$ was general corrosion. The quasipitting observed after $1.21 \times 10^{6} \mathrm{~s}$ was attributed to the incomplete dissolution of the air-formed film within a limited time of $1.21 \times 10^{6} \mathrm{~s}$. At the point B in Fig. 8 , the corrosion morphology was marginal between $\mathcal{N}$. and $L$ after $1.21 \times 10^{6} \mathrm{~s}$, but it changed to complete $L$ (pitting) after $1.56 \times 10^{7} \mathrm{~s}$. It is obvious from these results that the results of conventional immersion tests are significantly affected by the test duration. No changes in corrosion morphology due to prolongation of test duration were observed at the points $\mathrm{C}$ and $\mathrm{D}$.

\subsection{Prediction of "Passive to Active" Transition}

The $\mathrm{pH}_{a}$ is defined as a critical $\mathrm{pH}$ value for an alloy to exhibit passive to active and active to passive transition. Therefore, if the $\mathrm{pH}$ value of a given environment is known, it is possible to determine whether or not the alloy can be passivated in the environment. If the alloy cannot be passive, the passive film does not form on the alloy surface so that the corrosion morphology must be general corrosion (active dissolution). The corrosion morphology in a situation where the alloy is passive should be no attack or pitting. Since the passive film is quite unstable in the vicinity of passive to active transition, the critical environments for this transition should coincide with the boundary between pitting and general corrosion. Therefore the critical environments for general corrosion of an alloy can be predicted by comparing the

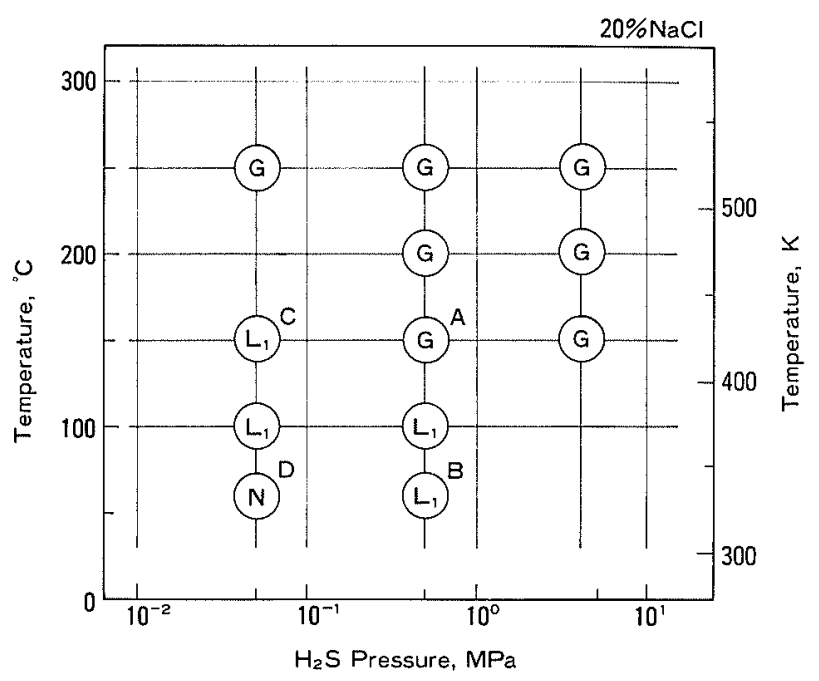

Fig. 8. Corrosion morphology of steel DIN as influenced by temperature and $\mathrm{H}_{2} \mathrm{~S}$ partial pressure.

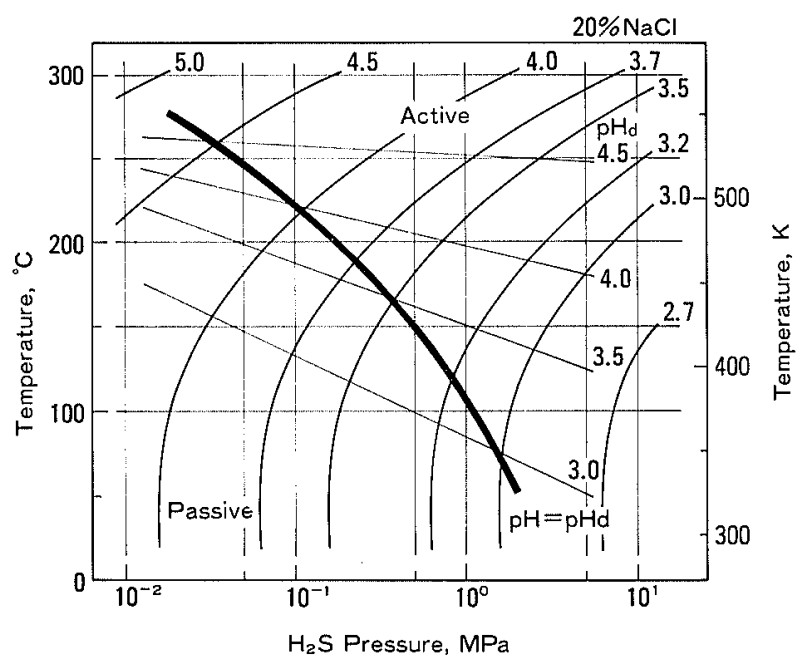

Fig. 9. Predicted critical environments for active-passive transition of steel DIN as a locus of the points representing $\mathrm{pH}=\mathrm{pH}_{d}$.

$\mathrm{pH}$ of environments with the $\mathrm{pH}_{d l}$ of the alloy as follows.

$\mathrm{pH}<\mathrm{pH}_{l l} ;$ active

$\mathrm{pH}>\mathrm{pH}_{l l}$; passive

Then the locus of the points representing $\mathrm{pH}=\mathrm{pH}_{d}$ gives the critical environment for passive to active transition. The $\mathrm{pH}_{d}$ can be determined by electrochemical measurements as mentioned above. A thermodynamic estimation technique was proposed ${ }^{10)}$ for the pH of a given environment. The validity of the estimation was confirmed by the $\mathrm{pH}$ measurements using a semiconductor-type $\mathrm{pH}$ sensor. ${ }^{10)}$

The critical environments for passive to active transition was determined by comparing equi- $\mathrm{pH}_{d}$ lines reported in Sec. 3.1 with equi-pH lines already reported in the literature ${ }^{10}$ ) and given in Fig. 9. Since this alloy is active in the upper-right region of the transition, the alloy exhibits general corrosion in this region. 


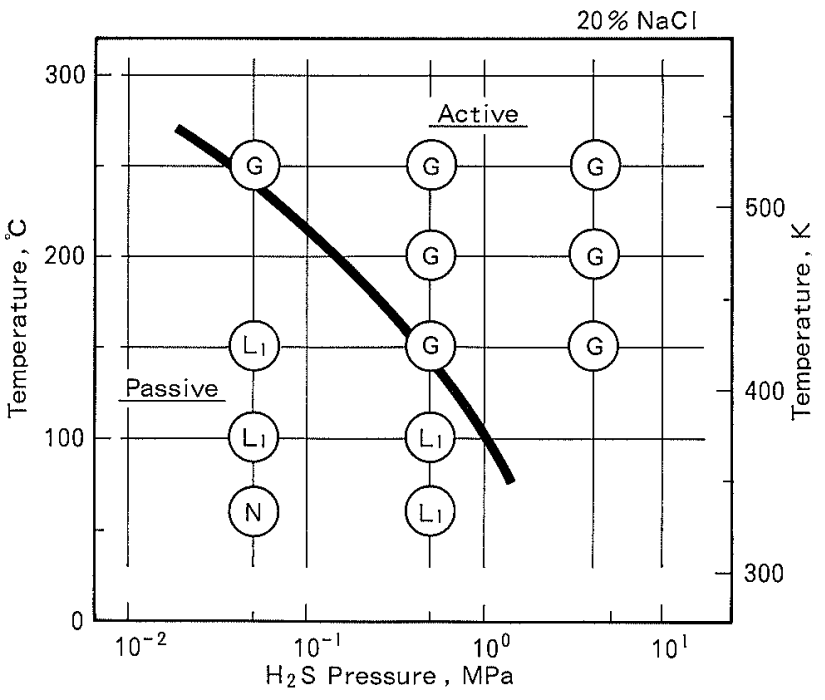

Fig. 10. Comparison between predicted critical environments for active-passive transition with observed corrosion morphology for steel DIN.

\subsection{Comparison of Electrochemical Prediction with Immer- sion Test Results}

Fig. 10 compares the electrochemically predicted critical environments for passive to active transition with the immersion test results of long term. Here the line in Fig. 10 is the predicted boundary for passive to active transition. As mentioned before this line should coincide with the boundary between pitting and general corrosion. The letters in the circles indicate the corrosion morphologies determined in the immersion tests. It is obvious from the figure that the electrochemically predicted transition is in good agreement with experimental results. The similarly good agreement between predicted and experimental results was also obtained for steel $316 \mathrm{~L}$. These clearly prove that the critical environments for passive to active transition can be predicted by the criterion proposed in Sec. 3.4 .

\subsection{Application of $\mathrm{pH}_{a}$ Prediction}

In actual oilfield environments, $\mathrm{H}_{2} \mathrm{~S}$ and $\mathrm{CO}_{2}$ coexist very frequently. $\mathrm{CO}_{2}$ does not affect the $\mathrm{pH}_{b}$ of CRAs as mentioned in Sec. 3.1. The effect of $\mathrm{GO}_{2}$ therefore is only to lower the $\mathrm{pH}$ of the aqueous solutions. The $\mathrm{pH}$ of sour environments shifts to a smaller value with an increase in $\mathrm{CO}_{2}$ partial pressure at a constant $\mathrm{H}_{2} \mathrm{~S}$ partial pressure. ${ }^{10)}$ Since $\mathrm{CO}_{2}$ does not affect the $\mathrm{pH}_{d}$ of $\mathrm{CRAs}$, the $\mathrm{pH}_{d}$ values obtained in $\mathrm{CO}_{2}$-free environments also stand for those in $\mathrm{CO}_{2}$ containing environments. Therefore, by comparing the $\mathrm{pH}_{d}$ values with the $\mathrm{pH}$ of the environments, which is a function of $\mathrm{H}_{2} \mathrm{~S}$ and $\mathrm{CO}_{2}$ partial pressures and temperature, the critical einvironments for active-passive transition can be determined as a function of $\mathrm{CO}_{2}$ partial pressure.

Fig. 11 shows the change in active and passive regions of alloy DIN due to an increase in $\mathrm{CO}_{2}$ partial pressure. In obtaining Fig. 11, the $\mathrm{pH}_{d}$ values measured in a $\mathrm{CO}_{2}$-free condition was used. The $\mathrm{pH}$ and

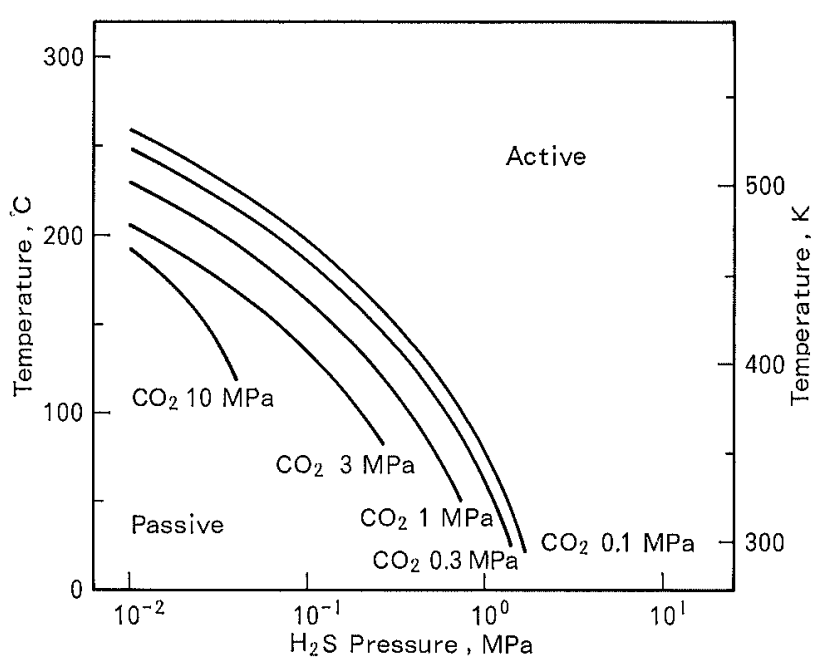

Fig. 11. Shift of predicted critical environments for activepassive transition with increasing $\mathrm{CO}_{2}$ partial pressure.

thus equi-pH lines as a function of $\mathrm{CO}_{2}$ partial pressure were calculated by the thermodynamic estimation. ${ }^{10)}$ The passive region tends to be confined to a lower $\mathrm{H}_{2} \mathrm{~S}$ pressure and lower temperature region with increasing $\mathrm{CO}_{2}$ partial pressure. This is the result of $\mathrm{pH}$ lowering of the environments caused by $\mathrm{CO}_{2}$.

\section{Conclusions}

The passivation behavior of corrosion resistant alloys in $\mathrm{H}_{2} \mathrm{~S}$-containing aqueous solutions was investigated and a criterion for predicting the critical environments for passive to active transition was examined. The following conclusions were obtained.

(1) Hydrogen sulfide was found to retard the passivation of alloys. The $\mathrm{pH}_{t}$ value changed to a larger value with a temperature rise and/or an increase in $\mathrm{H}_{2} \mathrm{~S}$ partial pressure.

(2) The $\mathrm{pH}_{a}$ values estimated from the anodic and cathodic polarization curves in active conditions agreed well with the measured ones.

(3) A new criterion to determine whether or not an alloy can be passive in a given environment was proposed; this can be determined by comparing the $\mathrm{pH}_{d}$ of the alloy with the $\mathrm{pH}$ of the environment. The validity of the prediction was confirmed by the fact that the predicted critical environments for passive to active transition were in good agreement with the immersion test results for long term.

(4) The proposed criterion has an advantage in that the results with $\mathrm{CO}_{2}$-free conditions can be used for the critical environments in $\mathrm{CO}_{2}$-containing environments, because $\mathrm{CO}_{2}$ does not affect the passivation behavior of corrosion resistant alloys.

The criterion determines the environments where GRAs cannot be used because they are active in the environments. This does not necessarily give information for the integrity of materials in a passive region. For such purpose the critical environments for localized corrosion and SGC must be determined. This will be discussed in another paper. 


\section{Acknowledgments}

The authors wish to express their thanks to Nippon Steel Corporation for allowing publication of this material. The discussions from co-workers in Nippon Steel's laboratories are gratefully acknowledged.

\section{REFERENCES}

1) S. W. Ciaraldi: Mater. Perf., 25 (1986), No. 1, 9.

2) For example, Proc. Int. Conf. Advanced Corrosion Resistant Steels and Metal Alloys Offshore, NITO (Norwegian Soc. Eng.), Oslo, (1987).

3) H. E. Chaung, M. Watkins and G. A. Vaughn: NAGE Corrosion/85, Pap. No. 227, Nat. Assoc. Corros. Eng.,
Houston, TX, (1985)

4) H. Miyuki, J. Murayama, T. Kudo and T. Moroishi: NACE Corrosion/84, Pap. No. 293, Nat. Assoc. Corros. Eng., Houston, TX, (1984).

5) T. Kudo, H. Miyuki, H. Okamoto, J. Murayama and T. Moroishi: NACE Corrosion/82, Pap. No. 127, Nat. Assoc. Corros. Eng., Houston, TX, (1982).

6) H. H. Uhlig: J. Electrochem. Soc., 108 (1961), 327.

7) H. Ogawa, I. Itoh, M. Nakada, Y. Hosoi and H. Okada: Telsu-to-Hagané, 63 (1977), 605.

8) H. P. Leckie: Corrosion, 24 (1968), 70.

9) J.M. West: Electrodeposition and Corrosion Processes, D. Van Nostrand Co. Ltd., London, (1965), 49.

10) A. Miyasaka, K. Denpo and H. Ogawa: ISIJ Int., 29 (1989), 85. 